\title{
Electronic Resources for Searching Health Scientific Information. Database Publication Type
}

\author{
Recursos Electrónicos para la Búsqueda de Información Científica \\ en Salud. Tipos de Bases de Datos de Publicaciones
}

Carlos Manterola ${ }^{* * * *}$; Tamara Otzen ${ }^{* * * * * * * *} \&$ Lilian Calo ${ }^{* * * * * *}$

MANTEROLA, C.; OTZEN, T. \& CALO, L. Electronic resources for searching health scientific information. Database publication type. Int. J. Morphol., 32(4):1484-1491, 2014.

SUMMARY: Despite the large amount of information available on the Internet, getting valid scientific information and evidence may not be a simple task. The aim of this study was to identify the different databases, search engines and libraries available to retrieve published scientific information in health sciences Database publication type. A search on Altavista, Google and Yahoo, Ixquick and Copérnico metasearch engines and in the database "Documents in Information Science" (DoIS) was performed. The search strategy used the terms "database management systems", "medical informatics", "search engine" and "decision making". A summary document of the information collected was created. Addresses found were grouped into: databases, search engines and libraries. The search performed returned 46 electronic resources: 25 databases, 8 search engines and 13 libraries. There is a variety of resources for searching health scientific information. Knowing the diversity of available options aids the user in access to information to generate research and health-related decision-making.

KEY WORDS: Database; Publication Type; Medical Informatics; Search engine; Decision making; Evidence-Based Medicine.

\section{INTRODUCTION}

Access to information is increasingly easy and userfriendly; however, the sheer volume and diversity of Internet sites has grown drastically, so it is common for users to feel overwhelmed by the amount of information, and sometimes question what is valid and what is not (Glowniak, 1995; Balatsouras et al., 2002; Eysenbach \& Diepgen, 1999; Jadad et al., 2000). In fact, there are those who maintain that "computer science in health" should be considered an academic discipline dedicated to the exploration of healthrelated subjects (Eysenbach \& Jadad, 2001).

In addition, accurate information from the results of health research is a fundamental topic; so much so that it is known that clinicians use approximately two million pieces of data to treat one patient (Smith, 1996; Eysenbach, 2000).

"Database" [publication type] is a MeSH and DeCS term introduced in 1998 by NCBI and in 2000 by Virtual Health Library (VHL) respectively as a type of publication that corresponds to the creation of a structured file of information or data that is logically related, stored and recovered using computer-based media (NCBI, 2013; Biblioteca Virtual en Salud, 2013). Such documents are relevant to decision-making in health care.

The aim of this article is to describe the different databases, search engines and libraries available to obtain published health science data.

\section{MATERIAL AND METHOD}

\section{Type of study: Publication of databases.}

Sources of information: A search was made on meta-search engines Ixquick and Copérnico, Google and Yahoo, and in the Documents in Information Science database (ScienceCentral, 2013) in the period April to August 2013. Search strategy: The following terms were used: "database

* Department of Surgery and Traumatology, Universidad de La Frontera, Temuco, Chile.

** Research Center in Biomedical Sciences, Universidad Autónoma de Chile, Temuco, Chile.

*** PhD Program in Medical Sciences, Universidad de La Frontera, Temuco, Chile.

***** School of Psychology, Universidad Autónoma de Chile, Temuco, Chile.

****** Latin-American and Caribbean Center on Health Science Information (BIREME/PAHO/WHO), Sao Paulo, Brasil. 
management systems", "medical informatics", "search engine", "health search engines", "medical search engines" and "decision making".

Handling: Data reading and extraction from the various sites was done independently by the three authors. Sessions of rough drafts with recovered information were created via electronic mail, from which the final document was developed, and this was the one discussed during in-person sessions. The resources found were grouped as follows: databases, search engines and libraries.

Definitions: A database was defined as a virtual source of information containing a set of primary source records belonging to the same context and stored systematically, such as a search engine, a computer system that looks for files stored on web servers. And like a library, digitized computer resource centers that include databases (Rodríguez Camiño, 2013; DORA, 2013).

\section{RESULTS}

The search yielded a total of 46 electronic resources: 25 databases, 8 search engines and 13 libraries; those described next are in alphabetical order by sub-group. The corresponding URLs are found in Table I.

\section{Databases}

1. BioMedCentral, British, contains 256 peer-reviewed journals with free access in all areas of medical research and biology.

2. BIOSIS Previews is part of Thomson Reuters' Web of Knowledge (WoK); it contains abstracts and indexed citations from 1926 to date. It has access to the contents of the main BIOSIS publications, abstracts, reports, conferences and reviews. It includes literature of pre-clinical and experimental research. It consists of 350,000 references from almost 5,000 journals, monograph titles and retrospective files.

3. CINAHL (Cumulative Index to Nursing and Allied Health Literature), related to nursing and associated fields, it provides access to health books, theses, proceedings from selected conferences, clinical practice guidelines, audiovisual documents and book chapters. It includes more than 70 complete text journals, as well as legal cases, research instruments and clinical trials. It uses MeSH terms for the searches.

4. Clinical Evidence, from the BMJ publishing group, contains selected analyses of systematic reviews (SR) and selected individual studies that assess the benefits and harms of treatments, and a set of evidence-based medical resources and training materials.

5. Current Contents Connect is part of Thomson Reuters. It provides complete access to tables of contents in journals, books, abstracts etc. with daily updates. It enables complex searches to locate specific information, and then stores the search history for later use. It also allows the user to receive weekly email alerts of updates of the stored searches.

6. DOAJ (Directory of Open Access Journals) is an openaccess scientific and academic list, administered and partially financed by the libraries of Lund University, Sweden. It currently includes 9,897 journals from 120 countries that contain 1,144,136 articles. DOAJ also participates in the WorldWideScience portal.

7. EBSCOhost, is owned by EBSCO Publishing. It groups several data bases: Academic Search Complete, Business Source Complete, ERIC, MedicLatina, Medline/full text, among others. Through its website searches can be performed by a thesaurus. It is a paid service.

8. Genamics Journal Seek, was developed by GenamicsTM. It has information about free-access journals with 100,400 titles. It can quickly identify new journals in order to publish scientific articles in the area of interest.

9. GetCITED is a database, directory and online discussion forum all in one. It contains bibliographical information published in scientific journals, books and book chapters as well as other publications such as conference proceedings. It has more than $3,425,000$ publications by more than 300,000 authors.

10. Global health is provided by CABI, Oxford. It specializes in public health and includes the main public health journals, as well as those not indexed by the main databases. It contains more than a million records from more than 3,500 periodicals, as well as books, conference proceedings and "grey" literature. It captures scientific material from 125 countries.

11. HINARI (Health InterNetwork Access to Research Initiative) offers access to more than 6,000 full-text journals related to the field of biomedecine and other related topics of social sciences applied to health. This initiative includes more than 150 publishing companies, the main ones being Lippincott Williams \& Wilkins, Nature Publishing Group, Oxford University Press, Science, Springer Link and WileyBlackwell. 
Table I. Sources of information and their electronic addresses.

\begin{tabular}{|c|c|c|}
\hline Source of information & Type of resource & URL \\
\hline BioMedCentral & DB & $\underline{\text { www.biomedcentral.com }}$ \\
\hline BIOSIS Previews & DB & wokinfo.com/products_tools/specialized/bci \\
\hline CINAHL & DB & www.cinahl.com \\
\hline Clinical Evidence & DB & $\underline{\text { Www.clinicalevidence.com }}$ \\
\hline Current Contents Connect & DB & thomsonreuters.com/current-contents-connect. \\
\hline DOAJ & DB & www.doaj.org \\
\hline EBSCOhost & DB & www.ebscohost.com \\
\hline Genamics JournalSeek & DB & journalseek.net \\
\hline GetCITED & DB & www.getcited.org \\
\hline Global health & DB & www .ebscohost.com/biomedical-libraries/global-health \\
\hline HINARI & DB & www.who.int/hinari/es \\
\hline IBECS & DB & www.isciii.es \\
\hline LILACS & DB & lilacs.bvsalud.org/es \\
\hline MEDLINE & DB & www.nlm.nih.gov/pubs/factsheets/medline.html \\
\hline Open J-gate & DB & openj-gate.org \\
\hline Pepsic & DB & pepsic.bvsalud.org \\
\hline PKP & DB & pkp.sfu.ca \\
\hline ProQUEST & DB & search.proquest.com \\
\hline PubMed & DB & www.ncbi.nlm.nih.gov/pubmed \\
\hline Rev@Enf & DB & www.revenf.bvs.br \\
\hline Science Direct & DB & www.sciencedirect.com \\
\hline SCOPUS & DB & $\underline{w w w . s c o p u s . c o m}$ \\
\hline SCImago & DB & Www.scimagojr.com \\
\hline TropIKA.net & DB & www.tropika.net/resources \\
\hline WHOLIS & DB & liscuba.sld.cu/index.php?P=FullRecord\&ID=1652 \\
\hline WoK & DB & webofknowle dge.com, http://wokinfo.com \\
\hline EMBASE & SE & www.elsevier.com/online-tools/embase \\
\hline Excelencia clínica & SE & www.msssi.gob.es/organizacion/sns/planCalidadSNS/ec00.htm \\
\hline Free journals act & SE & Www.freejournalsact.com \\
\hline Google Scholar & SE & scholar.google.com \\
\hline OVIDSp & SE & www.ovidsp.ovid.com \\
\hline SCIRUS & SE & www.scirus.com \\
\hline TRIP database & SE & www.tripdatabase.com \\
\hline VHL Search Portal & SE & www.bvsalud.org \\
\hline WorldCat & SE & www.worldcat.org \\
\hline APA & $\mathrm{L}$ & www.apa.org \\
\hline BIREME & $\mathrm{L}$ & regional.bvsalud.org \\
\hline CRD & $\mathrm{L}$ & www.york.ac.uk/inst/crd \\
\hline Digital.CSIC & $\mathrm{L}$ & digital.csic.es \\
\hline EZB & $\mathrm{L}$ & rzblx1.uni-regensburg.de/ezeit \\
\hline GeoLibrary & $\mathrm{L}$ & geolibrary.org \\
\hline Global health Library & $\mathrm{L}$ & www.globalhealthlibrary.net \\
\hline Latindex & $\mathrm{L}$ & www.latindex.org \\
\hline Ministry of Health Library & $\mathrm{L}$ & www.health.govt.nz/a bout-ministry/ministry-health-library \\
\hline Redalyc & $\mathrm{L}$ & www.redalyc.org \\
\hline ResearchBib & $\mathrm{L}$ & www.researchbib.com \\
\hline SciELO & $\mathrm{L}$ & www.scielo.org \\
\hline SciELO libros & $\mathrm{L}$ & books.scielo.org \\
\hline The Cochrane Library & $\mathrm{L}$ & $\underline{w w w}$ thecochranelibrary.com \\
\hline
\end{tabular}

$\mathrm{DB}=$ Database, $\mathrm{SE}=$ Search Engine, L= Library. 
12. IBECS (Health Sciences Spanish Bibliographic Index) is produced by the National Health Sciences Library of Instituto de Salud Carlos III (ISCIII) of Spain's Ministry of Health, Social Policy and Equality. It contains references to articles published in health journals edited in Spain from different disciplines such as Public Health, Epidemiology, Health Administration, Pharmacy, Psychology, Dentistry and Nursing.

13. LILACS (Latin American and Caribbean Health Sciences Literature), is a bibliographical index of health sciences literature published in the countries of Latin America and the Caribbean since 1982. It has more than 650,000 publications from around 860 journals. It also indexes theses, monographs, books and book chapters, conferences and conference proceedings, as well as governmental publications and those from regional international organizations, etc.

14. MEDLINE. Produced by the US National Library of Medicine (NLM) and the National Institutes of Health (NIH), it is an automated version of three printed indices: Index Medicus, Index to Dental Literature and International Nursing Index. A distinctive characteristic of MEDLINE is that the records are indexed with the NLM Medical Subject Headings (MeSH®). It collects bibliographical references from articles published in 4,800 medical journals from 1966 to date with more than 22 million references from approximately 5,600 journals worldwide in 39 languages. It is the primary component of PubMed and part of the Entrez databases provided by the NLM National Center for Biotechnology Information (NCBI).

15. Open J-gate. Organized by Informática Ltda. (India), it was launched in February 2006. It has more than a million free-access articles from more than 13,750 journals, and this increases annually by approximately 300,000 new articles.

16. Pepsic (Electronic Periodicals in Psychology). It contains 128 open access journals, 2,060 issues and 27,388 articles with periodic updates published according to the SciELO methodology, although they are not part of the SciELO collection.

17. PKP (Public Knowledge Project) is an open source journal management and publishing system that has been developed by the federally funded Public Knowledge Project from Canada. It disseminates scientific material produced by universities and research centers including publications, teaching material, PowerPoint presentations, etc.

18. ProQUEST. Created by the publishing company ProQuest LLC (Cambridge Information Group). It includes eight thematic areas: Arts, Social Sciences, Science and Technology; Economics and Business; History, Language and Literature; Health and Medicine; Doctoral Theses and Dissertations. The area of Health and Medicine contains 5 databases: ProQuest Career and Technical Education: Health \& Medicine; ProQuest Dissertations \& Theses: Health \& Medicine; ProQuest Health \& Medical Complete; ProQuest Nursing \& Allied Health Source; ProQuest Research Library: Health \& Medicine. It is a paid service.

19. PubMed, created by the US National Library of Medicine and the National Institutes of Health, includes more than 23 million references in biomedical literature. This includes MEDLINE, biological sciences journals and books. The references may contain links to the complete free text from the PubMed platform or from the websites of the journals themselves. The searches can be performed using MeSH terms. In addition, it has special tools such as "search history" and "clinical queries", and it can save searches for later reviews.

20. Rev@Enf (Electronic Periodicals in Nursing). It contains 27 open access journals, 772 issues and 14.245 articles published according to the SciELO methodology. Also in this case, they are not part of the SciELO collection.

21. Science Direct, is sponsored by Elsevier. It includes more than 11 million articles from more than 2,500 journals, book chapters and close to 20,000 books. These are grouped in sections (Physical Sciences and Engineering, Life Sciences, Health Sciences, and Social Sciences and Humanities). For most of the articles the abstracts are free access; access to the full text requires payment.

22. SCOPUS, edited by Elsevier, includes abstracts and references from articles in scientific journals from 1996. It covers approximately 20,000 journals in the areas of sciences, technology, medicine and social sciences. Of these, almost 2,600 are open access. It also contains more than 350 book series and around 3,800 articles in press. The searches incorporate the Scirus and Elsevier databases. It also offers authors' profiles number of references of publications, etc. It has additional services such as Scopus Author Preview and SCImago Journal \& Country Rank, the later being an open access database.

23. TropIKA.net (Tropical Diseases Research to Foster Innovation \& Knowledge Application) is has been developed by the Special Program of Research and Teaching about Tropical Diseases (TDR). It is based on the web of povertyrelated infectious diseases (IDPs).

24. WHOLIS (locates information about health in the World Health Organization). WHO library information system 
based in Havana, Cuba. It offers publications from the headquarters of the organization and regional representations, journal articles, texts, technical and official documents.

25. WoK (Web of Knowledge) is integrated into Thomson Reuters (previously Institute for Scientific Information, ISI). It is an access portal to a combination of databases and other resources that include all fields of knowledge (Web of Science, Conference Proceedings Citation Index, Journal Citation Reports, Essential Science IndicatorsSM, Current Contents Connect ${ }^{\circledR}$, etc.). It also includes bibliographical databases, with references from more than 12,000 journals in science and technology, social sciences, and arts and humanities through its services and products: Science Citation Index (SCI), Science Citation Index Expanded (SCI-E), Social Sciences Citation Index (SSCI), Arts \& Humanities Citation Index (A\&HCI), Biological Abstracts, Index Chemicus and Current Chemical Reactions. It is a paid service.

\section{Search Engines}

1. EMBASE provides information regarding treatment of diseases, drugs in general, new drugs and new applications of already existing drugs. It allows users to recover articles that could not be found in other search engines. It currently has a source of more than 25 million records of approximately 7,000 journals from 70 countries. It can use MeSH terms. In addition, it has all the content from MEDLINE and more than 5 million articles and papers that are only indexed on EMBASE.

2. Free Journals Act can search in open-access scientific journals by thematic area, approaching all the areas of the biological sciences. It has the support of 180 scientific journals.

3. Google Scholar specialized in articles from scientific journals. It is supported by a freely available database that includes books, theses, abstracts, etc. It includes Elsevier journals. It can calculate authors' h-index. It cannot perform searches with limits by type of publication or research methodology, nor can it perform searches through MeSH and related terms.

4. OVIDSp is part of the Ovid Technologies platform. It includes databases for Medicine (MEDLINE, EMBASE, Psycinfo, Current Contents, etc.), Engineering, Architecture, etc. Basic, advanced and multifield searches are possible. It also has a search update alert via electronic mail. It is available in English, French, German, Japanese, Chinese and Spanish.
5. SCIRUS was created by the Dutch publishing house Elsevier in 2001. It has 13 million patents from the US, Europe and Japan, and more than 250 million indexed websites. It also provides search channels narrowed by content and categories like "medicine" or "psychology". It does not allow searches with limits by type of publication or methodology used, or searches with MeSH terms. There is no free-access content.

6. Search Portal of the Virtual Health Library, is an open access engine that integrates multiple health databases such as Medline, LILACS, The Cochrane Library, IBECS, PAHO, WHOLIS, MedCarib, and others. Searches can be performed using the controlled vocabulary DeCS, which is the Spanish, English and Portuguese thesaurus derived from MeSH.

7. TRIP database was created by the Faculty of Medicine at the University of Wales as part of the CeReS (Centre for Research Support) project. It emphasizes evidence-based medicine and clinical guidelines (includes content from Cochrane and Bandolera). It has more than 17,000 references belonging to 60 databases. Based on this search engine, Spain's Ministry of Health created "Clinical excellence", a meta-search engine specializing in information about scientific evidence that enables the integrated search of several resources, including: Agencies for Health Technology Assessment, Cochrane database, Bandolera, Fisterra, MedlinePlus, SciELO, etc.

8. WorldCat (World Catalog), is a free-access search engine. It houses files and records from more than 72,000 of the world's libraries. It groups two billion elements, including books, DVDs, CDs and articles, in 470 languages. It can consult with the libraries about the searches and keep the reviews made to contribute with other users.

\section{Libraries}

1. APA (American Psychological Association) includes several databases: PsycINFO®, PsycARTICLES ${ }^{\circledR}$, PsycBOOKS®, PsycTESTS $®$, PsycTHERAPY®, etc., as well as PsycINFO®, which is the greatest resource of abstracts in behavioral sciences and mental health literature. It is updated weekly and contains documents from the 19th century to date.

2. BIREME (Latin American and Caribbean Center on Health Sciences Information) was founded in 1967 and it is a PAHO/WHO specialized Center. Its main goal is contribute to health equity in the countries of the Latin America and the Caribbean by means of the democratization of access, publication and use of the health information, knowledge and scientific evidence. Its program model is the 
VHL, which through its electronic portal offers access to bibliographical references in Spanish, Portuguese and English mainly of scientific production in Latin America and the Caribbean. The VHL portal provides access to scientific articles, monographs, conference proceedings, theses, etc. It contains subportals (LILACS, Evidence Portal, DeCS, Health Sciences Journals and SCAD Cooperative Service for Accessing Documents); international databases (LILACS, MEDLINE and MEDCARIB); databases of international entities (PAHO and WHOLIS); national databases (BBO, BDENF, Index Psi Divulgación científica, IBECS, Cochrane Library and Cochrane Plus, Primary Health Care, etc.). It also contains an evidence portal and other tools and services such as the DeCS (Health Sciences Descriptors, a thesaurus derived from $\mathrm{MeSH})$.

3. CRD (Centre for Reviews and Dissemination) is part of the National Institute for Health Research (NIHR) and the University of York. It has three databases: DARE (Database of Abstracts of Reviews of Effectiveness), NHS EED (National Health Service Economics Evaluation Database) and HTA (Health Technology Assesment Database). It is updated daily and provides information on more than 20,000 SR of diagnostic and therapeutic efficacy, 13,000 economic evaluations, and 12,000 abstracts of completed and on-going health technology assessments.

4. Digital.CSIC (Superior Council for Scientific Research) is an open-access project coordinated by the Scientific Information for Research Resources Unit (URICI), in which the entire CSIC Library and Archive Network of Spain actively participates. It allows access to complete scientific publications created in the CSIC. It includes information about various Spanish scientific communities such as Biology and Biomedecine, Food Science and Technology, etc.

5. EZB (Electronic Journals Library) has the technical support of the Regensburg University Library, Germany. It is supported by 490 libraries and research centers operated through a central database which is maintained cooperatively. It provides access to the full text of online journals. It can perform article searches by thematic area or journal title.

6. GeoLibrary is a global library of training materials in environmental and occupational health. It was founded by WHO in 2003 as a collaboration project. It contains databases and resources on subjects of safety, occupational health and environmental health. It is divided into three sections: environmental materials, occupational health materials and occupational safety on the road.
7. Global Health Library was developes by WHO in collaboration with BIREME. It includes scientific and technical literature from a series of regional libraries (Africa-AFRO, Americas-AMRO/OPAS, Eastern MediterraneanEMRO, Europe-Euro, Southeast Asia-SEARO and Western Pacific-WPRO) and networks (TropIKA, e-PORTUGUÉSe and EVIP.Net) as well as other types of services. Searches can be made using DeCS.

8. Latindex (Regional Cooperative Online Information System for Scholarly Journals from Latin America, the Caribbean, Spain and Portugal) specializes in openaccess journals published in Ibero-America. It is the result of collaboration among various institutions from 23 countries. It includes four databases of Ibero-American academic journals: Directory, Catalog, Electronic Journals and a portal to portals.

9. Ministry of Health Library Catalogue, created by the New Zealand Ministry of Health, contains Ministry publications and reference indexes of printed resources in the Ministry's Library and Information Center. It is comprised of approximately 15,000 books and 250 journal subscriptions classified by category. It is open-access.

10. Redalyc (Red de Revistas Científicas de América Latina y el Caribe), an open access project started by the Universidad Autónoma de México in 2002. It includes journals from Latin America, Spain and Portugal. It has incorporated tools for analyzing the production, dissemination and consumption of scientific literature (catalogs, abstracts, full texts, etc.). It contains more than 250 journals, 2,200 fascicles and more than 27,000 full-text articles.

11. ResearchBib is an open-access publishing system for academic resources. It is free and anyone enrolled can freely submit or edit publications, graduate research programs, articles from scientific magazines, etc. There is also a ranking by country of the aforementioned fields. In addition it offers banners, links to increase the impact factor and conversation channels.

12. SciELO (Scientific Electronic Library) is a project initiative by FAPESP, FapUnifesp and BIREME. It enables the electronic publishing of scientific journals through an open-access platform. Currently, the following countries are participating in the SciELO network: Argentina, Brazil, Chile, Colombia, Cuba, Spain, Mexico, Portugal, South Africa and Venezuela. In addition, the following collection is under development: Bolivia, Costa Rica, Peru and Uruguay. SciELO also has an additional service called SciELO books, a book catalog that has 406 titles available from 1,844 authors, 259 of which are open access. It also has 3,636 open- 
access book chapters that can be downloaded in formats such as PDF and ePUB.

13. The Cochrane Library is a non-profit organization established in the United Kingdom. It prepares, maintains and disseminates Systematic Reviews (SR) of controlled clinical trials in health care, as well as reviews of evidence derived from other sources. It is divided into the following sections: The Cochrane Database of Systematic Reviews (CDSR), which contains SR performed by the Cochrane Collaboration, as well as protocols and titles; Cochrane Central Register of Controlled Trials (CENTRAL), which includes controlled trials and other studies of health care interventions; Database of Abstract of Reviews of Effects (DARE), which provides abstracts of reviews of effects; Cochrane Methodology Register, which contains information on methodology; Health Technology Assessments Database, which collects data on completed and on-going health technology assessments; Economic Evaluations Resources, which include economic evaluations; and Cochrane Groups, which collects data on SR by review groups (CRGs).

\section{DISCUSSION}

Despite the large amount of existing resources (including those that could have been fortuitously omitted in this article), it seems essential to us to indicate that we verified the existence of an abundant amount of information overlapping among them, which makes the use of duplicate elimination filters indispensable.

All this would seem to indicate that the visibility of an article does not have much to do with the database where it is indexed, because the results of our search show that visibility is associated, among other things, to the availability in open access of articles, the knowledge of the modus operandi of each database or simply to the predilection to use some resources instead of others, possibly out of ignorance of the existence of other alternatives, some of which provide open access to the full text of the article one wishes to locate.

Another item that determines the increased use of an article is the impact factor (IF) of the journal where it has been published. In this respect, it seems fundamental to us to stress that index-linking in the WoK is not synonymous with IF, since not all the journals indexed in WoK are incorporated into JCR (a different database from Thomson Reuters, who assigns the IF). For example, to date, of the 18,711 journals indexed in WoK corresponding to all areas of the knowledge, only 8,471 (45.3\%) are incorporated into
JCR; therefore, the mere fact of having an IF itself highlights this reduced number of journals. It seems to us that the measurement must be through the number of citations of an article. Proof of this is the San Francisco Declaration on Research Assessment (DORA), a document signed by renowned scientists and academic organizations, including the American Society for Cell Biology (ASCB), the American Association for the Advancement of Science, as well as a group of directors and publishers of scientific journals, who have made known the need to improve the way in which the results of scientific research are assessed in terms of the excessive use of IF. They have even suggested when it should not be used (evaluations related to financing, promotions in career, hiring of academics, etc.). Furthermore, there is evidence that a journal's IF and its visibility given by this indicator are not necessarily associated with the methodological quality of the articles published in it (Manterola et al., 2006; Manterola \& Grande, 2010).

As previously indicated, it seems to us that this article is a contribution for those who wish to have more information about the electronic resources available, and particularly for those who conduct SR, given that their adequate development requires the use of several databases to decrease the bias inherent in such a design (Manterola et al., 2013).

In view of these results, we believe that this is an interesting line of work, from which it may be possible to produce contributions aimed at creating guidelines for the use of each of these resources in order to optimize efficient searches (since each of these has its own search methodologies), to compare two or more databases for which there is already evidence (Giustini \& Barsky, 2005; Shultz, 2007), among others.

MANTEROLA, C.; OTZEN, T. \& CALO, L. Recursos electrónicos para la búsqueda de información científica en salud. Tipos de base de datos de publicaciones. Int. J. Morphol., 32(4):14841491, 2014.

RESUMEN: A pesar de la gran cantidad de información disponible en Internet, la obtención de información científica válida y evidente puede no ser una tarea sencilla. El objetivo fue identificar las diferentes bases de datos, motores de búsqueda y bibliotecas disponibles para recuperar la información científica publicada en ciencias de la salud. Estudio de publicación de base de datos. Se realizó una búsqueda en los metabuscadores Altavista, Google, Yahoo, Ixquick y Copérnico, y en la base de datos "Documents in Information Science" (DoIS). La estrategia de búsqueda utilizó los términos "sistemas de gestión de base de datos", "informática médica", "motor de búsqueda" y "toma de decisiones". Se creó un documento de síntesis de la información recogida. Las direcciones halladas se agruparon en: bases de datos, motores de búsqueda y bibliotecas. A partir de la búsqueda realizada se encontraron 46 
fuentes electrónicas: 25 bases de datos, 8 motores de búsqueda y 13 bibliotecas. Existe una gran variedad de recursos para la búsqueda de información científica en salud. Conocer la diversidad de opciones disponibles en el acceso a la información ayuda al usuario para llevar adelante su investigación y para poder realizar la toma de decisiones relacionada con la salud.

PAlABRAS ClaVE: Base de datos; Tipo de Publicación; Informática Médica; Motor de búsqueda; Toma de decisiones; Medicina Basada en la Evidencia.

\section{REFERENCES}

Balatsouras, D. G.; Kaberos, A.; Korres, S. G.; Kandiloros, D.; Ferekidis, E. \& Economou, C. Internet resources available to otolaryngologists. Ann. Otol. Rhinol. Laryngol., 111(12 Pt. 1):1139-43, 2002.

Biblioteca Virtual en Salud. DeCs. Database. 2013. Disponible en: http://decs.bvs.br/cgi-bin/wxis1660.exe/decsserver/

DORA. Declaration on Research Assessment. 2013. Disponible en: http://am.ascb.org/dora

Eysenbach, G. \& Diepgen, T. L. Labeling and filtering of medical information on the Internet. Methods Inf. Med., 38(2):80-8, 1999.

Eysenbach, G. Consumer health informatics. BMJ, 320(7251):1713-6, 2000.

Eysenbach, G. \& Jadad, A. R. Evidence-based patient choice and consumer health informatics in the Internet age. J. Med. Internet Res., 3(2):E19, 2001.

Giustini, D. \& Barsky, E. A look at Google Scholar, PubMed, and Scirus: comparisons and recommendations. JCHLA, 26:85-9, 2005 .

Glowniak, J. V. Medical resources on the Internet. Ann. Intern. Med., 123(2):123-31, 1995.

Jadad, A. R.; Haynes, R. B.; Hunt, D. \& Browman, G. P. The Internet and evidence-based decision-making: a needed synergy for efficient knowledge management in health care. CMA J., 162(3):362-5, 2000.

Manterola, C.; Pineda, V.; Vial, M.; Losada, H. \& MINCIR Group. What is the methodologic quality of human therapy studies in ISI surgical publications? Ann. Surg., 244(5):827-32, 2006.

Manterola, C. \& Grande, L. Methodological quality of articles on therapeutic procedures published in Cirugía Española. Evaluation of the period 2005-2008. Cir. Esp., 87(4):244-50, 2010 .
Manterola, C.; Astudillo, P.; Arias, E.; Claros, N. \& Grupo MINCIR (Metodología e Investigación en Cirugía). Systematic reviews of the literature: what should be known about them. Cir. Esp., 91(3):149-55, 2013.

NCBI. MeSH. Database [Publication Type]. 2013. Disponible en: http://www.ncbi.nlm.nih.gov/mesh/68019991

Rodríguez Camiño, R. Motores de búsqueda sobre salud en Internet. ACIMED, 2003:11(5), 2003. Disponible en: http://bvs.sld.cu/ revistas/aci/vol11_5_03/aci02503.htm.

ScienceCentral. Documents in Information Science" (DoIS). 2013. Disponible en: http://www.sciencecentral.com/site/518669

Shultz, M. Comparing test searches in PubMed and Google Scholar. J. Med. Libr. Assoc., 95(4):442-5, 2007.

Smith, R. What clinical information do doctors need? BMJ, 313(7064):1062-8, 1996.

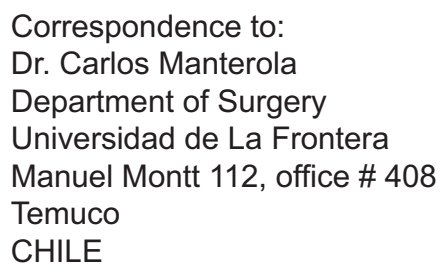

Email:carlos.manterola@ufrontera.cl

Received: 09-09-2014

Accepted: 16-10-2014 